DOI: $10.12957 /$ teias.\%Y.42999

\title{
A EDUCAÇÃO DAS FAMÍLIAS POR OFÉLIA BOISSON CARDOSO: uma leitura da obra Problemas da Adolescência
}

\author{
Evelyn de Almeida Orlando \\ Henllyger Estevam David
}

\section{Resumo}

O presente artigo tem como objetivo discutir a partir da análise da obra Problemas da adolescência, publicada em 1961, a contribuição da intelectual Ofélia Boisson Cardoso para a educação das famílias. Metodologicamente, buscamos ler a obra em sua materialidade e em seu conteúdo, visando compreender os saberes que a autora pretendia transmitir a seus leitores. A pesquisa se consolidou na perspectiva da História Cultural, tendo como metodologia a análise do livro como fonte documental privilegiada (LE GOFF, 1990). A partir da análise do impresso podemos concluir como os princípios cristãos, mais especificamente católicos, nortearam a problemática discutida pela autora, possibilitando que suas produções servissem também como instrumento de moralização das famílias brasileiras.

Palavras-chave: educação das famílias; ideologia católica; impresso pedagógico; ofélia boisson cardoso.

\section{THE EDUCATION OF FAMILIES BY OFELIA BOISSON CARDOSO:} a reading of the work Problems of Adolescence

\section{Abstract}

This article aims to discuss from the analysis of the work Problems of adolescence, published in 1961 the contribution of the intellectual Ofélia Boisson Cardoso to the education of families. Methodologically, we seek to read the work in its materiality and content, aiming to understand the knowledge that the author intended to transmit to her readers. The research was consolidated in the perspective of Cultural History, using the methodology of analyzing the book as a privileged documentary source (LE GOFF, 1990). From the analysis of the printed matter, we can conclude how Christian principles, more specifically Catholic, guided the problem discussed by the author, enabling her productions to also serve as an instrument for the moralization of Brazilian families.

Keywords: education of families; catholic ideology; printed pedagogical; ofélia boisson cardoso.

\section{LA EDUCACIÓN DE LAS FAMILIAS POR OFÉLIA BOISSON CARDOSO:}

\author{
na lectura de la obra Problemas de la Adolescencia
}

Resumen

Este artículo pretende analizar a partir del análisis de la obra Problemas de la adolescencia, publicada en 1961, la contribución de la intelectual Ofélia Boisson Cardoso a la educación de las familias. Metodológicamente, buscamos leer el trabajo en su materialidad y contenido, con el objetivo de comprender el conocimiento que el autor pretendía transmitir a sus lectores. La investigación se consolidó en la perspectiva de la Historia Cultural, utilizando la metodología de análisis del libro como fuente documental privilegiada (LE GOFF, 1990). Del análisis del material impreso, podemos concluir cómo los principios cristianos, más específicamente católicos, guiaron el problema discutido por la autora, permitiendo que sus producciones también sirvan como un instrumento para la moralización de las familias brasileñas.

Palabras clave: educación de las famílias; ideología católica; impreso pedagógico; ofélia boisson cardoso. 


\section{INTRODUÇÃO}

Desde o início do século XX, a educação das famílias se apresentou com uma preocupação da sociedade brasileira, mobilizando diferentes educadores escolanovistas ${ }^{1}$ e católicos no desenvolvimento de projetos que preparassem as famílias para o cumprimento de seu papel na formação do cidadão e, consequentemente, na organização da sociedade.

Neste sentido, esta temática se apresenta como um fértil espaço de debate no campo histórico educacional, auxiliando na composição do papel assumido por diferentes grupos em relação às famílias e nas estratégias que foram mobilizadas na direção de sua educação e se constitui como parte de uma pesquisa de mestrado ${ }^{2}$.

O presente artigo tem como objetivo discutir a contribuição da intelectual Ofélia Boisson Cardoso para a educação das famílias a partir da obra Problemas da adolescência, publicada em 1961 pela Editora Melhoramentos, chegando a quatro reedições ${ }^{3}$. O exemplar analisado foi o da terceira edição, datada de 1965.

Metodologicamente, objetivou-se ler a obra em sua materialidade e em seu conteúdo, compreendendo os saberes que a autora procurava discutir. Luca $(2015$, p. 139) sinaliza que o historiador "[...] dispõe de ferramentas provenientes da análise do discurso que problematizam a identificação imediata e linear entre a narração do acontecimento e o próprio acontecimento". Nesse sentido, ao utilizar como ferramenta a análise do discurso, possibilitou-se uma ideia clara de como Ofélia delineou seu discurso atrelado às necessidades educacionais da época.

Esta investigação se torna relevante no campo da História da Educação à medida que “[...] os estudos centrados nos usos pedagógicos do impresso podem trazer uma inteligibilidade nova sobre a história da escola e dos saberes e práticas que a constroem" (CARVALHO, VIDAL, 2000, p. 7).

Buscando localizar outros trabalhos sobre impressos destinados à educação das famílias, foram consultados o banco de teses e dissertações da CAPES, o IBICT, revistas da área de história da educação e outras plataformas em busca de trabalhos que auxiliassem na reflexão dos objetivos deste artigo.

A partir deste levantamento destacamos as principais investigações sobre educação das famílias e projetos de educação familiar que vêm sendo desenvolvidos no âmbito da História da Educação, chamando a atenção para os diferentes grupos envolvidos com esse objetivo e as diferentes estratégias que foram mobilizadas nessa direção. Destacamos aqui as teses Lições de casa: discursos pedagógicos destinados à família no Brasil, de Ana Maria Bandeira de Mello Magaldi (2001) ${ }^{4}$; Educar-se para educar: o projeto pedagógico do Monsenhor Álvaro Negromonte dirigido a professoras e famílias através de impressos (1936-1964), de Evelyn de Almeida Orlando (2013)5; e

\footnotetext{
${ }^{1}$ Apesar do embate consolidado entre escolanovistas e católicos, a intelectual Ofélia Boisson Cardoso não demonstrava em suas obras tal situação, antes alinhava em seu discurso ideias de ambos os grupos.

2 Pesquisa gestada no âmbito do projeto Educação, Gênero e Cristianismo: circulação, representação, formação e práticas femininas em cenário religioso e educativo, com financiamento do Conselho Nacional de Desenvolvimento Científico e Tecnológico - CNPQ, no Edital Universal 2016.

3 Os respectivos anos das reedições da obra são: $1^{\mathrm{a}}$ edição, S/D; $2^{\mathrm{a}}$ edição, 1961; $3^{\mathrm{a}}$ edição, 1965; $4^{\mathrm{a}}$ edição, 1967; $5^{\mathrm{a}}$ edição, 1969.

${ }^{4}$ Sinaliza como os intelectuais “[...] imbuídos de uma missão 'civilizadora' conduziram importantes iniciativas nessa direção, como parte de projetos mais amplos de organização da sociedade brasileira" (MAGALDI, 2001, p. 23).

5 Assinala como as práticas culturais "[...] visaram estabelecer novos códigos de valores e comportamentos, criaram outras representações para o educador, associando as contribuições pedagógicas dos novos tempos aos saberes elementares da fé católica” (ORLANDO, 2013, p. 15).
} 
Família, mulher e prole: a doutrina social da Igreja e a política social do Estado Novo, de Cynthia Pereira de Souza Vilhena $(1988)^{6}$.

Destacamos, sob a ótica católica, algumas pesquisas que nos auxiliam na compreensão de como os grupos católicos traçaram estratégias objetivando a educação familiar: a dissertação Sob o simbolo da cruæ: Questão social, família e educação nas relações entre Estado e Igreja no Brasil (19301945), de Luciandra Gonçalves da Silva (2010) ${ }^{7}$; e Ministro de Deus, portador da luz: Ações e discursos católicos de modelação docente na década de 1930, de Rodrigo Mota Narcizo (2008) $)^{8}$. Essas pesquisas oferecem proximidade com a pesquisa proposta e são indicativos da consolidação de um movimento de aproximação da escola e da sociedade, buscando educar a família para cooperar com a formação do cidadão.

Este artigo se consolidou na perspectiva da História Cultural, em estreito diálogo com a História do Livro e dos Impressos, tendo como metodologia a análise documental, e o livro como fonte privilegiada da análise.

Pensar na trajetória histórica do livro e em sua imersão no cotidiano social significa compreender que "[...] é, no seu conjunto, uma mercadoria produzida e vendida, é o suporte de conteúdos culturais e é igualmente um objeto físico, específico nos seus materiais, na sua organização e fabrico" (CHARTIER, 1999, p. 121). Neste sentido, pode-se entender ainda a partir do conceito de documento, apoiado em Le Goff (1990), o qual afirma que "[...] o documento para o historiador não é qualquer coisa que fica por conta do passado, é um produto da sociedade que o fabricou segundo as relações de forças que se estabeleceram nessa produção"(LE GOFF, 1990, p. 545). Neste caso, os documentos e livros analisados são entendidos na perspectiva de documentos/monumentos, oferecendo um ensaio de um projeto educacional voltado para as famílias brasileiras, do qual Ofélia participou com notada legitimidade.

\section{OFÉLIA BOISSON CARDOSO NA COLEÇÃO BIBLIOTECA DE EDUCAÇÃO DIRIGIDA POR LOURENÇO FILHO}

A presença de uma autora na coleção Biblioteca de Educação nos chamou atenção pelo lugar privilegiado ocupado no empreendimento editorial dirigido por um intelectual da Educação que se tornou conhecido como um dos importantes pilares do grupo dos pioneiros da Educação Nova. Apesar do rótulo, Lourenço Filho foi um intelectual da educação e político que soube transitar em diferentes grupos e espaços do campo educacional e político.

A Coleção Biblioteca de Educação, um dos principais empreendimentos editoriais que Lourenço Filho dirigiu, foi um espaço no qual "[...] referências teóricas e científicas abraçadas pelo educador encontraram um importante veículo de difusão no Brasil [...]” (SOARES, 2010, p. 161). A coleção buscava colocar em circulação conhecimentos das áreas educativas e da psicologia direcionados ao professorado primário e a todos aqueles interessados nas temáticas relacionadas à educação, por exemplo as famílias.

Fazer parte de uma coleção como autora significa figurar entre autores selecionados e ter leituras prescritas por alguém que possui prestígio suficiente junto ao público-leitor, que se pensa

\footnotetext{
6 O trabalho versa sobre a efetivação dos projetos do Estado Novo e da Igreja Católica com o objetivo de disciplinamento da família.

7 A dissertação indica como houve uma influência significativa do ideário católico no cenário educacional e político brasileiro no período do Estado Novo.

${ }^{8}$ Discorre sobre os diálogos existentes entre católicos e escolanovistas.
} 
DOI: $10.12957 /$ teias. $\%$ Y.42999

como destinatários privilegiados daquele empreendimento editorial; significa pertencer a um grupo seleto, avalizado e legitimado para o público, o que confere a este(a) autor(a), além do status, uma difusão maior de sua obra e a garantia da obra comprada.

[...] escolha do nome do organizador, do ponto de vista de uma editora comercial, deveria garantir o convencimento do público que a seleção ali operada, sobretudo quando se trata de livros científicos, seria confiável e serviria para os fins determinados pela apresentação da coleção. O nome do organizador é a garantia da obra comprada pelo público; é a chave de sua difusão. (CARVALHO, TOLEDO, 2013, p. 99)

Além disso, significa também fazer parte de um lugar de poder, de uma política cultural que, em diálogo com outras instâncias do jogo político, afirma-se também pelo livro, como objeto cultural e por suas prescrições de leitura. Segundo Carvalho e Toledo (2013, p. 2),

[...] a edição de coleções é sempre produto de uma dupla inserção em um lugar de poder: de um lado, a de um interesse econômico de uma casa de edição, marcada por uma lógica que visa à ampliação do mercado editorial; de outro, a de uma política cultural que deposita no livro uma missão, variável segundo os objetivos que lhe são atribuídos por seus promotores, em situações históricas específicas.

A visão apresentada pelas autoras em relação à construção de uma coleção tem como objetivo, do ponto de vista econômico, cooptar mais leitores. Ao mesmo tempo, a prática de orientar leituras tem como objetivo conduzir os(as) leitores(as) a um determinado caminho de formação pela exposição a determinados saberes e ideias e conhecimento, dos quais espera-se que ele se aproprie. No caso da coleção Biblioteca de Educação, podemos perceber que Educação e Psicologia andavam lado a lado, e isso se materializava nos títulos da coleção, sugerindo aos(às) leitores(as) que essas duas áreas estavam intrinsecamente articuladas. Tal representação também evidenciava o tom dos debates educacionais e assegurava um lugar privilegiado a um dos modelos em disputa no mercado editorial.

Ofélia Boisson Cardoso não foi a única mulher a ter suas obras publicadas na coleção", porém foi a mais publicada, somando um total de cinco títulos, a saber: Problemas da infância; Problemas da adolescência; Problemas da meninice; Problemas da mocidade e Problemas da família. Em seus estudos, Cardoso atentou para todas as fases de desenvolvimento do indivíduo e seus potenciais problemas, dando exemplos vividos em sua experiência como mãe, professora e psicóloga, buscando contribuir para a educação das famílias no Brasil.

Como autora, Ofélia ainda se valia de outra estratégia editorial muito característica da Coleção Biblioteca da Educação: todos os seus livros eram prefaciados pelo próprio Lourenço Filho, ressaltando sua dedicação ao campo educacional e a contribuição que suas pesquisas traziam para a educação brasileira.

\footnotetext{
9 Elementos de Psicologia, de Iva Waisberg Bonow; Pequena história da educação, de Madres Peters e Cooman, e Supervisão do ensino médio, de Nair Fortes Abu-Merhy.
} 
DOI: $10.12957 /$ teias.\%Y.42999

\section{LENDO PROBLEMAS DA ADOLESCÊNCIA A PARTIR DA MATERIALIDADE DA OBRA}

O livro Problemas da adolescência, escrito por Ofélia Boisson Cardoso, teve sua primeira publicação possivelmente em $1961^{10}$, quando os jornais da época ${ }^{11}$ passaram a anunciá-lo como importante leitura para as famílias que buscavam embasamento científico e técnico para a educação dos filhos. Neste sentido, faz-se necessário observar como se consolidava o contexto cultural e histórico da época em que a obra foi posta em circulação.

Os anos de 1960 são marcados pela queda de investimentos no país, aumento da inflação, entre outros problemas sociais não resolvidos nas décadas anteriores. Pinsky (2014, p. 21) cita ainda a "aventura política" vivenciada até 1964, "[...] marcada por palavras de ordem como nacionalismo, desenvolvimentismo ou reforma e por agitações sociais significativas", as quais resultaram no Golpe Militar. Na década de 1960, há um avanço nas discussões acerca da emancipação feminina, momento também em que a intelectual demonstrou mais circulação e produção em sua trajetória. Pinsky (2014, p. 19) salienta que, em virtude das discussões a respeito da autonomia feminina ${ }^{12}$, houve "[...] maior probabilidade das mulheres no mercado de trabalho". Um conjunto de mudanças sociais serviu como reforço para que as concepções tradicionais da família viessem à tona, colocando-as em xeque, já que não representavam a estrutura familiar brasileira. Muitos trabalhos da intelectual versavam sobre o papel da mulher na maternidade e a importância da consciência do papel que elas deveriam desempenhar no âmbito doméstico.

A edição analisada por esta pesquisa foi publicada em 1965. Observando o livro em sua materialidade, é possível identificar que a capa apresenta harmonia em relação às demais capas da coleção neste período e chama a atenção do leitor pelo uso de cores fortes, com formas e linhas limpas e bem delimitadas. Neste sentido, Orlando (2008, p. 78), destaca que

A produção de uma coleção tem como característica básica a padronização em termos de cobertura, de estrutura interna e de estratégias de divulgação, com o objetivo de baratear os custos de cada livro produzido, tornando-o acessível a uma nova classe de leitores que antes não tinha acesso a esse produto.

A similaridade entre as obras também instiga visualmente o leitor a identificar o livro como parte dessa coleção, criando uma identidade visual que as aproxima e leva o(a) leitor(a) a associálas.

$\mathrm{Na}$ figura 1, podemos visualizar alguns aspectos relacionados à organização visual da capa do livro em questão.

\footnotetext{
10 A primeira edição não apresenta o ano de publicação, mas é em 1961 que a obra é mencionada e indicada nos jornais pela primeira vez.

${ }^{11}$ Jornal do Brasil, Diario de Noticias, O Jornal, Correio da Manhã, Jornal do Commercio, Última Hora, Correio Paulistano, Diario Carioca, Manchete, Diario da Noite, Revista do Livro, Letras da Província, A Cigana, A luta democrática, Tribuna da Imprensa, A noite, Jornal do Dia, Leitura, O Estado de Florianópolis, O Cruzeiro, Diario de Pernambuco, O Fluminense, O Mundo Ilustrado, O Repórter, Diarios de Notícias do Paraná.

12 A emancipação feminina sinalizava uma ameaça à moral familiar e religiosa da época.
} 
Figura 1: Capa do livro Problemas da adolescência

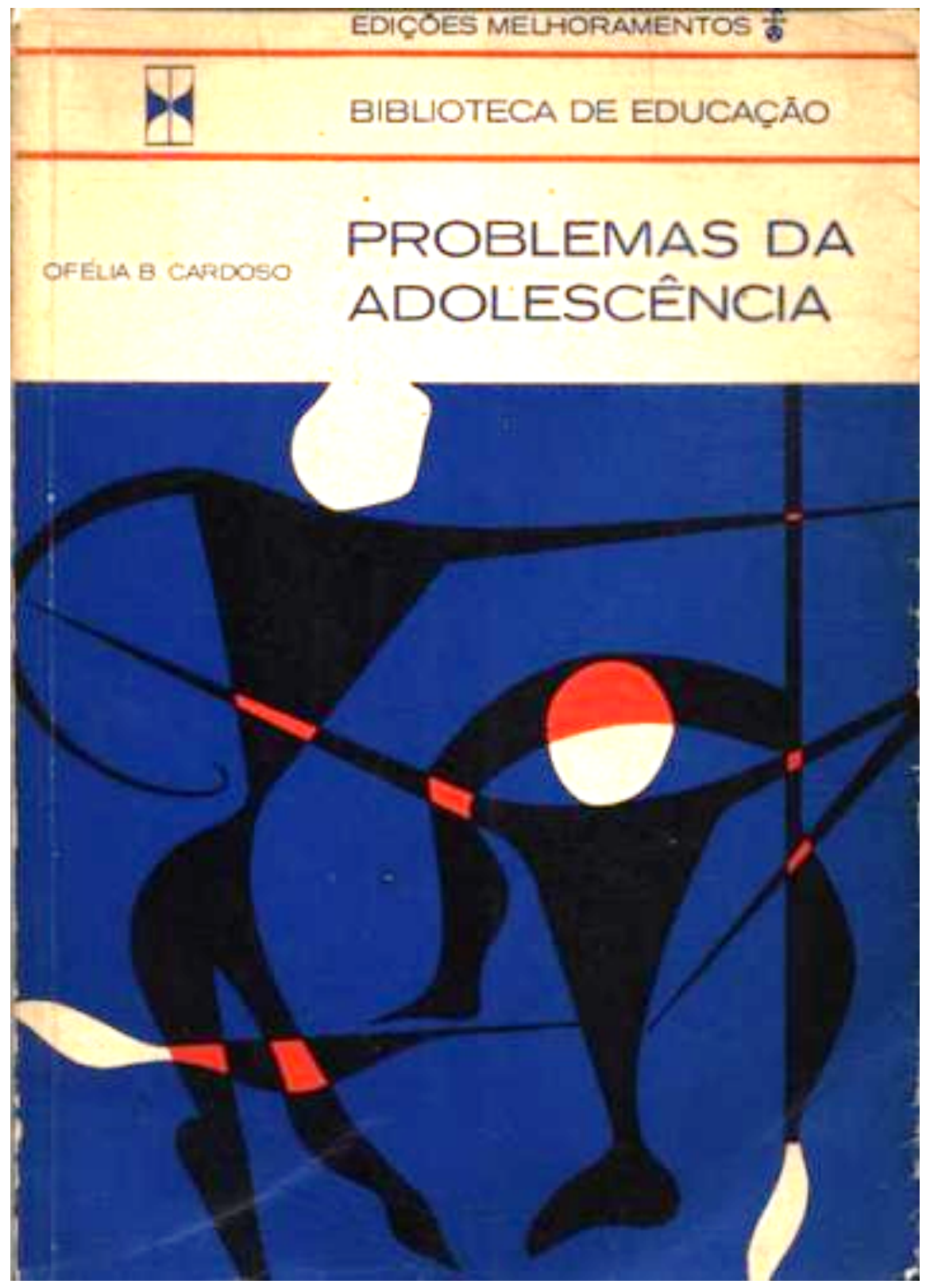

Fonte: Acervo particular das pesquisadoras

Observando a figura, podemos identificar que as cores predominantes na capa são: azul cobalto, preto, vermelho e marfim claro. Em uma análise é possível também visualizar um desenho que remete à figura de um adulto e outro que pode ser interpretado como um adolescente. Outra interpretação possível é a ideia de que ilustração remete a movimento, podendo ser indicativa de características dessa fase, marcada por várias descobertas e transformações.

O título da obra foi escrito em letras caixa alta e alinhado à direita. Em primeiro plano está escrito Problemas da adolescência, distribuído em duas linhas, no segundo plano aparece o nome da coleção a qual o livro pertence, no terceiro aparece o nome da editora e, no quarto, ao lado do 
título, aparece o nome da autora. A diferença de tamanho entre as fontes utilizadas na capa indica que o livro se destaca pela problemática anunciada e pelo pertencimento à Biblioteca de Educação.

Observando a palavra "problema" destacada em primeiro plano, pode-se relacioná-la com as demais obras produzidas pela autora na coleção, remetendo à ideia de que independentemente do problema vivido no âmbito familiar a autora teria estudos que poderiam subsidiar a atuação dos pais em qualquer faixa etária de desenvolvimento dos filhos.

$\mathrm{Na}$ lombada do livro aparecem as duas cores predominantes da capa - azul cobalto e castanho claro - com o título do livro e o nome da autora escritos em caixa alta, aparecendo ainda um símbolo representando a editora. O formato de brochura permite que o livro seja mais acessível ao leitor. Além disso, "[...] a costura dos cadernos substitui a colagem nos livros mais bemacabados, o que confere uma capacidade de manuseio mais segura e durável" (ARAÚJO apud ORLANDO, 2008, p. 78).

A contracapa apresenta coloração castanho claro com letras grifadas em cor azul cobalto em diferentes formatos. São apresentadas em primeiro plano as outras obras escritas pela autora no âmbito da coleção. Essa exposição das pesquisas que a autora vinha realizando na área era estratégica tanto do ponto de vista mercadológico quanto cultural; em relação ao mercado, contribuía para a venda do livro; em relação ao campo cultural, tais referências serviam como estratégias de legitimação da obra para um público mais especialista, como professores ou psicólogos, e para aqueles pais ávidos por terem contato com as contribuições que o campo científico oferecia sobre a temática.

No centro da contracapa aparece um pequeno texto escrito em caixa baixa, trazendo um endosso da importância do livro, relatando que a pesquisa foi baseada em pesquisa científica.

Baseada nos depoimentos de pais e filhos, na informação de mestres e parentes
e valendo-se ainda das provas psicológicas a Prof. ${ }^{~}$ Ofélia Boisson Cardoso
realiza o mais atual e substancioso inquérito sôbre a infância, a meninice e a
adolescência desajustadas e expõe os vários aspectos dos problemas
(CARDOSO, 1965, p. 240)

Trazer os depoimentos de pais, filhos ${ }^{13}$, mestres e outros personagens, além da experiência da autora como profissional da educação e psicologia, confere à obra o status de cientificidade, com uma linguagem clara, acessível e profundamente identificada com a realidade de seus(suas) potenciais leitores/as. No final da página há uma nota em negrito e caixa alta reforçando que os livros faziam parte da coleção Biblioteca de Educação da Editora Melhoramentos.

$\mathrm{Na}$ orelha do livro na primeira linha aparecem novamente o nome da coleção, o título do livro, o nome da autora e um fragmento do prefácio redigido por Lourenço Filho, em caixa baixa com tamanho pequeno.

A obra apresenta duas folhas de rosto; na primeira, contém somente o nome da obra; na segunda, na parte superior da página, há o nome da autora em letras caixa alta, e em seguida uma breve descrição das atividades e cargos por ela desempenhados nos campos da Educação e da Psicologia. O título da obra distribuiu-se em duas linhas centralizadas. No verso da segunda folha de rosto há dados sobre a editora e a gráfica que produziram a obra e uma lista das outras obras publicadas pela autora na coleção, funcionando como um protocolo de prescrição de leituras atestadas pela editora, e também um endosso da referida autora, estratégia editorial utilizada para ampliar a visibilidade do autor em questão.

13 "filhos" refere-se aos pacientes atendidos pela autora. 
Na terceira página da obra há uma dedicatória ao seu filho Armando Vitor - "Lembrança de sua adolescência" - que remete, de modo sutil, à experiência materna vivida pela autora e a aproxima de suas leitoras pelas vivências que extrapolam o âmbito profissional e reforçam o argumento de autoridade do seu discurso.

Há, ainda, uma epígrafe de Rousseau, de sua obra Emilio, ressaltando a importância do desenvolvimento do humano e o abandono da infância como um progresso necessário e natural. Baseada em autores como Piaget e Freud e em outras pesquisas contemporâneas realizadas na área, Boisson vai imprimindo traços de cientificidade ao seu discurso sobre as diferentes fases pelo qual o ser humano passa. Gruber (1963, p. 17) destaca que

Durante mucho tempo predominó la opinión de que el desarrollo puberal constituía una mera manifestación de uma transformación biológica. Posteriormente, se reconoció que los juicios y los valores, así como las vivencias de representaciones de los sentidos y las ideias, son factores decisivos del desarrollo interior. Más recientemente, se ha señalado insistentemente el incremento de los problemas de la pubertad resultante de la actual crisis social y cultural.

O autor produziu esta pesquisa no mesmo período em que Cardoso discutia os problemas que afetam a adolescência. É interessante observar como o autor problematiza a importância da discussão e da tomada de atitude frente a esses problemas que estavam aparecendo de forma frenética na sociedade ocidental.

No prefácio da obra, distribuído ao longo de cinco páginas, Lourenço Filho reitera a importância dos livros escritos por Ofélia Boisson Cardoso, endossando para todos os que se preocupavam com os problemas educativos relacionados à adolescência. Segundo o educador, a autora merecia, portanto, uma boa acolhida de todos aqueles que se propusessem à árdua missão de educar. Ele destaca que os mais de 30 anos que a autora dedicou à área da psicologia e educação, além de obter a "[...] experiência de mãe de família e educadora consumada habilita-a a perceber as circunstâncias de cada caso com maior compreensão humana" (LOURENÇO FILHO, 1965, p. 10). A estratégia editorial de destacar as experiências pessoais e profissionais da autora já no prefácio oferece voz de autoridade à Ofélia para quem não a conhece e reforça a contribuição de suas obras tanto pelo caráter científico como pelo conhecimento empírico, adquirido na experiência da maternidade.

O uso dessa estratégia está diretamente associado, na perspectiva editorial, ao lugar que os prefácios ocupam como protocolos de leitura em uma obra. Fazendo um paralelo com a análise que Faria Filho (2017) faz sobre os prefácios das obras de Rui Barbosa, por exemplo, podemos fazer junto com ele uma análise similar aos prefácios das obras de Ofélia Boisson. Segundo Faria Filho (2017, p. 67), os textos de Rui Barbosa podem ser entendidos como "[...] um discurso primeiro sobre o qual os prefaciadores, como comentadores que são, trabalham para fazer falar o que nele estava inscrito ou oculto, atribuindo-lhe uma riqueza e atualizando seus múltiplos sentidos".

Mas, para além de servir como comentário das obras, os prefácios podem ser entendidos ainda seguindo a linha de análise proposta por Faria Filho, embasada em Foucault, Chartier e Certeau - também como lugares não apenas de repetição ou decifração do texto que está sendo comentado, mas de criação de um discurso próprio que produz novos sentidos sobre as obras, por serem resultados de práticas de leitura, as quais, segundo Chartier (2014, p. 123), se constituem como "[...] uma prática criadora, atividade produtora de sentidos singulares, de significações de 
DOI: $10.12957 /$ teias.\%Y.42999

modo nenhum redutíveis às intenções dos autores de textos ou fazedores de livros". Nesse sentido, para escrever um prefácio é necessário antes que o autor deste tenha lido a obra. E é exatamente aí que se elabora, primeiramente, como leitor dela e, depois, como escritor de um segundo discurso que tem por finalidade pôr em evidência o que está inscrito silenciosamente no texto primeiro. "[...] Daí também a ambivalência da posição do comentador: ele é o leitor que busca extrair ou construir sentidos do texto comentado e, ao mesmo tempo, o escritor que busca disciplinar as interpretações possíveis a respeito do texto comentado" (FARIA FILHO, 2017, p. 83).

Finalmente, o sumário apresentando a obra em nove partes, a saber: Introdução; Capítulo I - que trata da visão geral dos problemas da adolescência; Capítulo II - Cinco jovens e seus problemas; Capítulo III - Os casos de Beatriz; Carlúcio; Ciro Heliana e Ivã; Capítulo IV - Jorge, Júlio, Luciana, Marília, e os irmãos Nélson e Francisco; Capítulo V - Paulo, Salustiano, Sílvio, Sara e Timóteo; Capítulo VI - Quatro casos finais; Capítulo VII - Como evitar os problemas e encaminhar as soluções; e as Considerações Finais.

\section{LIÇÕES PARA EDUCAR OS ADOLESCENTES}

Segundo Ofélia, seu livro não busca apresentar conselhos ou críticas às famílias, mas oferecer suas experiências profissionais e pessoais que obteve com a criação dos filhos. Destaca o descaso dos jovens com os saberes construídos ao longo do tempo, caracterizando um abismo entre o passado e o presente. A perpetuação desses conhecimentos, para ela, só seria possível se os jovens dessem importância e conservassem os valores morais, intelectuais e sentimentais que são consolidados no seio familiar.

Essa valorização dos comportamentos morais da época nos remete à ideia de civilização, tal como propõe pensar Elias (2006). A autora entendia que a escolha consciente dos comportamentos adequados e a autorregulação dos indivíduos ajudaria na consolidação de uma sociedade civilizada e moralmente preparada para o desenvolvimento, tanto no aspecto econômico quanto moral, e defendia que a constituição de bons hábitos se reverteria em benefícios às instituições sociais ${ }^{14}$, as quais, por sua vez, também deveriam contribuir para a formação da sociedade.

A produção de Ofélia Boisson Cardoso como autora reforçava, portanto, o projeto de sociedade civilizada que se pretendia formar no Brasil desde o início da República, articulando os saberes científicos à moralização da nação por meio dos valores cristãos. Civilização e moral católica andavam lado a lado nesse projeto para o qual Ofélia contribuía, a partir de suas obras.

Ao longo de toda a obra, a autora se apoia em exemplos do seu cotidiano e os utiliza como lições de moral, como faz, por exemplo, já na introdução, na qual aponta o caso de um menino que, ao nascer a irmã mais nova, "perdeu" a atenção dos pais, o que contribuiu para o fortalecimento de comportamentos difíceis na escola, em casa e outros espaços que frequentava. Em um trecho, Cardoso (1965, p. 18) destaca que o menino desejou que o pai sumisse. "[...] O pai não 'sumiu', mas o pensamento também nunca mais 'sumiu' da cabeça da criança; mais tarde teve remorso vago, nebuloso, quando foi estudar o catecismo e aprendeu que era um grande pecado não amar os pais". Em outro trecho ${ }^{15}$ do livro Problemas na Adolescência, a autora sinaliza a mesma situação em que o menino sente "remorso" remetendo-se aos princípios cristãos apreendidos na

\footnotetext{
${ }^{14}$ Considerando como instituições sociais aquelas que buscam formar os sujeitos em diferentes aspectos e estratégias, como por exemplo o Estado, Igreja, a Família, a Escola, entre outros.

${ }^{15}$ Livro publicado em 1961 pela Editora Melhoramentos.
} 
DOI: $10.12957 /$ teias.\%Y.42999

catequese. Isso é indicativo da relevante presença de ideais católicos nos escritos de Ofélia Boisson e uma das principais bases de suas orientações pedagógicas. A autora mostra grande preocupação com os conflitos entre pais e filhos adolescentes, com prejuízos à relação e à harmonia familiar.

No primeiro capítulo, a obra trata, em uma perspectiva geral, dos problemas apresentados na adolescência. No primeiro parágrafo, a autora demarca seu pioneirismo no Brasil ao publicar obras desse tipo, voltadas para pensar as diferentes fases de desenvolvimento do indivíduo, destacando seus livros anteriores relacionados à infância, meninice e mocidade, além deste, voltado para os adolescentes, ressaltando que até então havia disponíveis no Brasil somente obras que tratavam destas questões escritas em inglês, francês e espanhol.

A estratégia de demarcar um espaço, no entanto, faz Ofélia ignorar discussões voltadas para essa temática no interior do próprio campo religioso católico. Em 1939, Alceu Amoroso Lima já havia publicado $A$ crise do adolescente, em colaboração com diversos autores que vinham se debruçando sobre o tema. Em que pese as diferenças dos tipos de problemas que os adolescentes e suas famílias enfrentavam nos anos de 1940 e 1960, iniciativas como essa mostram que já havia não apenas a preocupação com tal fase da vida e seus problemas por intelectuais e educadores católicos, como estes vinham produzindo livros nessa direção. O diferencial da obra de Ofélia, e isso sim a torna um diferencial entre as demais obras, é a sistematização que ela faz em relação ao tema, apoiada em critérios científicos, e o pertencimento a uma importante coleção do campo educacional.

Além disso, livros produzidos para a educação das famílias já vinham sendo produzidos por diferentes intelectuais, juntamente com uma diversidade de ações encaminhadas nessa direção. Muitas dessas questões eram trabalhadas até mesmo na formação de professores, por meio de disciplinas como Economia Doméstica, Trabalhos Manuais, Moral, entre outras. Levando em consideração que a tônica do início do século XX era a constituição de um projeto de nação e uma identidade nacional, a educação das famílias significava um importante passo para a conquista destes objetivos.

Ao longo do livro, a autora marca de forma recorrente sua atuação profissional ao discutir a temática, não se prendendo apenas aos aspectos práticos das problemáticas apresentadas. Ao longo do texto traz autores como Jean Piaget, Claparède, René Hubert, Hans Binder, Henri Wallon, Pavlov, William Stern, Robert Woodworth, Cyril Burt, Charlotte Bühler, Spranger, entre outros personagens importantes para a psicologia e para a educação. É interessante observar que ao longo da obra Cardoso não apresenta nenhum autor brasileiro que discute a temática, nem em âmbito geral da educação das famílias, algo que merece atenção, já que autores como o padre Álvaro Negromonte e a educadora Maria Junqueira Schmidt, entre outros educadores católicos, já haviam publicado livros sobre o assunto.

No segundo e terceiro capítulos, Ofélia apresenta alguns casos diferentes e seus respectivos problemas, assemelhando a metodologia empregada aos estudos de caso, dos quais tirava lições de moral e de pedagogia.

No terceiro capítulo, por exemplo, o caso de Beatriz aborda o problema da diferença religiosa na família, a partir da seguinte situação: um pai católico, uma mãe ortodoxa e muitas desavenças familiares, pois as famílias não aceitavam o casamento entre os dois, de religiões distintas. Nesse contexto, apresenta os sermões de um padre chamado Xavier ${ }^{16}$ e cita o nome de Deus diversas vezes ao relatar o problema da adolescente. Casos como esses acentuam o forte

16 Sem nenhum tipo de apresentação do padre, entende-se que seus sermões serviam como orientações pela legitimidade que a autoridade religiosa e institucional dava a quem o proferia. 
conteúdo religioso e moral que perpassava a obra, chegando muitas vezes a ser o mote das problemáticas anunciadas.

Mesmo problema de outra natureza, Ofélia utilizava as tintas da moralidade para analisálos e culpa, muitas vezes, os homens por não apresentarem o devido cuidado com a família, criando problemas estruturais pela ausência de valores morais na consolidação do elo familiar, como no que caso em que relata o despreparo de um pai para a paternidade: "[...] desde os primeiros meses de nosso casamento, se mostrou egoísta e irresponsável. [...] Raul nunca se interessou pelo filho" (CARDOSO, 1965, p. 92).

No quarto capítulo, Ofélia relata os problemas de Jorge, Júlio, Luciana, Marília e os irmãos Nelson e Francisco, destacando que um paciente "[...] só frequentou escola (religiosa, onde a disciplina é mais severa)" e mesmo assim o adolescente apresentava comportamentos difíceis (CARDOSO, 1965, p. 114).

Nos capítulos seguintes, a autora apresenta vinte e cinco casos de adolescentes "problemas". Os depoimentos foram transcritos gravados e taquigrafados. Alguns foram corrigidos "[...] quando a forma era por demais imperfeita e dava margem à confusão, ou quando havia erros mais sérios de linguagem" (CARDOSO, 1965, p. 195). As entrevistas foram feitas com onze meninas e quatorze meninos adolescentes. Esse tipo de inferência busca legitimar a metodologia empregada na coleta de dados, realçando o caráter científico do trabalho, resultado de pesquisa científica. Os casos selecionados pela autora são discutidos de forma aleatória para ilustrar algumas problemáticas enfrentadas no ambiente doméstico.

Nas considerações, Ofélia enfoca a dimensão do afeto no desenvolvimento do indivíduo e defende que todo ser humano precisa ter certeza de ser amado, querido no âmbito familiar, principalmente pelos pais. Para ela, a figura dos pais é basilar na evolução emocional do indivíduo. O processo de identificação com o genitor do mesmo sexo concorreria para a autoafirmação e, portanto, para emancipação progressiva do genitor do sexo oposto. Os problemas infantis e juvenis devem ser solucionados no lar.

Para a autora, a família constitui-se no ambiente mais propicio à evolução do ser. Sua harmonia, com a devida orientação, possibilitaria a solução de qualquer problema, simples ou complexo. Mas, para tanto, os filhos precisariam sentir-se como parte integrante dela.

Ofélia destaca que sempre que os pais entram em conflito, as crianças ficam suscetíveis à fragilidade emocional, o que pode torná-las indivíduos instáveis, impossibilitados de obter um autocontrole emocional. Esta afirmação de causa e efeito apresentada pela autora pode ser entendida também como uma estratégia de inibir os pais de comportamentos moralmente deturpados.

Em relação à orientação educacional, a autora ressalta a valorização do pediatra como figura importante na saúde da criança e na garantia do bem-estar familiar. Cardoso destaca que "[...] Os filhos não são 'coisas' que pertençam aos pais; integram-se na humanidade, considerada essa integração num sentido mais amplo; vivem em determinada sociedade e num determinado momento, num sentido mais limitado" (CARDOSO, 1965, p. 221).

A autora destaca que " $[. .$.$] conceber é fenômeno natural, decorrência moral do casamento.$ Não existe uma virtude especial, nem um ato excepcional em conceber. Assistir a prole é dever natural dos pais" (CARDOSO, 1965, p. 221). Nesse trecho, a representação do sexo associado ao casamento e para fins de procriação é abordada como consequência natural. Ao mesmo tempo, ao naturalizar o ato de conceber, Ofélia desmistificava a sacralidade da concepção, humanizando-a e inserindo-a dentro de um processo racional e moral da época. 
Essa moral em relação à sexualidade pode ser entendida, segundo Pinsky (1997, p. 610), como um comportamento ideal para as moças de família que

[...] eram as que se portavam corretamente, de modo a não ficarem mal faladas. Tinham gestos contidos, respeitavam os pais, preparavam-se adequadamente para o casamento, conservavam sua inocência sexual e não se deixavam levar por intimidades físicas com os rapazes. Eram aconselhadas a comportarem-se de acordo com os princípios morais aceitos pela sociedade, mantendo-se virgens até o matrimônio enquanto aos rapazes era permitido ter experiências sexuais.

Ofélia ilustra um comportamento inapropriado nesse sentido, tomando como exemplo o caso de uma menina que foi flagrada pela mãe beijando o primo mais velho. A autora ressalta que "[...] Gilda, evidentemente, não estava informada sôbre o valor moral de um beijo" (CARDOSO, 1965, p. 229). Em seguida, relata que a menina foi punida pelo comportamento inadequado. É curioso observar que essa moral era polarizada, uma vez que somente ela foi censurada. Para o menino, muitas vezes, essas descobertas eram vistas com bons olhos e afirmavam sua masculinidade.

Em vários outros trechos do livro, Ofélia retoma a necessidade de as meninas continuarem castas até o casamento, reforçando os códigos morais que as mulheres deveriam obedecer na época. Neste caso, pode-se observar que, para os meninos, a autora incentivava que

[...] a figura paterna é de alta significação no ajustamento emocional da criança, mas sobretudo do menino [...] A posição que os pais assumem diante de dois problemas capitais na vida humana - casamento e profissão - é fundamental e pesa definitivamente na vida futura da prole (CARDOSO, 1965, p. 230-231)

A autora ainda assinala que:

Todo esforço do adolescente visa sua sobrevivência social; ele condensa as forças agressivas que, na infância, se aplicavam em trabalho, em criação, orientada e estimulada pelo meio em torno de um objetivo: "auto afirmar-se", ser "um" no meio da coletividade, com expressão própria; A adolescência pode parecer muito cruel; pode apresentar reações, que julgadas sem mais detida atenção impressionem pela dureza e impiedade (CARDOSO, 1965, p. 225-226)

Ofélia sinaliza que o período de transição entre a infância e a adolescência é marcada por muitos desafios. Neste sentido, Alceu Amoroso Lima, importante personagem da intelectualidade católica que também organizou uma obra sobre essa temática já mencionada anteriormente, destacava no final dos anos de 1930 que esta fase "[...] é um campo de batalha entre paixões e a vontade, entre o transbordamento máximo das forças vitais instintivas e o sol da consciência já formada" (LIMA, s/d, p. 73). Ou seja, entendia-se que pais bem preparados eram fundamentais para lidar com este equilíbrio, garantindo um bom desenvolvimento para os filhos, o que justifica o empenho da intelectualidade católica na missão de orientá-los e formá-los nos melhores caminhos pedagógicos e muni-los dos conhecimentos dos saberes científicos sem abrir mão dos pilares morais que deveriam constituir uma das bases desse tripé formativo.

Os vinte e cinco casos apresentados no livro são descritos com muitos detalhes pela autora, ressaltando comportamentos específicos de adolescentes, mas enfatizando que "[...] o ser humano deve evoluir o mais naturalmente possível. As frustrações são inevitáveis, para que se possa viver 
em grupo dentro de uma determinada cultura. Já essas bastam para preocupar pais e educadores" (CARDOSO, 1965, p. 235).

Neste caso, a ideia de educação das famílias mediado por Ofélia por meio de seus livros visava possibilitar um preparo dos pais para atuar nesta "evolução necessária" do indivíduo, tal como afirma a autora, com ações que viabilizassem um desenvolvimento saudável aos filhos.

\section{CONSIDERAÇÕES FINAIS}

A partir da análise da obra Problema da Adolescência, escrita por Ofélia Boisson Cardoso e publicada em 1961, a ideia de educação familiar endereçada pela autora à sociedade, apesar da articulação com autores do campo científico e da metodologia empregada, era permeada de princípios cristãos que norteavam a problemática discutida pela autora e evidenciam um projeto de moralização da nação pela educação das famílias.

A articulação entre exemplos vivenciados em sua experiência profissional e na própria educação dos filhos no discurso intelectual da autora faz com que ela se apresente ao público com legitimidade para discutir tal temática.

Além disso, o pertencimento à coleção Biblioteca de Educação indica o pertencimento a uma rede de sociabilidade da qual participam figuras ilustres do campo da intelectualidade brasileira e um alinhamento aos projetos educacionais em voga para a nação. Tais projetos, ainda que em disputa muitas vezes, apresentavam pontos em comum que permitiam a muitos desses intelectuais livre trânsito entre diferentes grupos, o que facilitava sua circulação em diferentes espaços de poder.

As obras de Ofélia Boisson Cardoso foram postas em circulação em uma das principais editoras do país, no âmbito de uma importante coleção, o que indica a chancela que recebeu de alguns pares do campo intelectual e o amplo alcance de suas ideias a um vasto público leitor.

\section{REFERÊNCIAS}

CARDOSO, Ofélia Boisson. Problemas da Adolescência. São Paulo: Melhoramentos, 1961.

CARVALHO, Marta Maria Chagas de; VIDAL, Diana Gonçalves (org.). Biblioteca e formação docente: percursos de leitura (1902-1935). Belo Horizonte/São Paulo: Autêntica, 2000.

CHARTIER, Roger. O que é um autor? Revisão de uma genealogia. Tradução Luzmara Curcino e Carlos Eduardo de Oliveira Bezerra. São Carlos, SP: EduFSCar, 2014.

CHARTIER, Roger. Leituras e leitores "populares" da renascença ao período clássico. In: CAVALLO, Guclielmo; CHARTIER, Roger. História da leitura no mundo ocidental. São Paulo, Ática, 1999.

ELIAS, Norbert. Escritos \& ensaios: Estado, processo, opinião pública. Rio de Janeiro: Jorge Zahar, 2006. Disponível em https://books.google.com.br/books?id=$\underline{\text { AFFoNG0mzUC\&printsec }}=$ frontcover\&dq $=$ norbert + elias + escritos $+\mathrm{e}+$ ensaios $\& \mathrm{hl}=\mathrm{pt}-$ $\underline{B R \& s a}=X \&$ redir esc $=\mathrm{y} \# \mathrm{v}=$ onepage $\& q \& \mathrm{f}=$ false. . Acesso em 2 jul. 2017.

FARIA FILHO, Luciano Mendes de. Edição e sociabilidade intelectuais: a publicação das obras completas de Rui Barbosa (1930-1949). Belo Horizonte: Autêntica Editora UFMG, 2017.

GRUBER, Alois. La pubertad. Barcelona: Editorial Herder, 1963.

LE GOFF, Jacques. História e Memória. Campinas, SP: UNICAMP, 1990. 
LIMA, Alceu Amoroso. Idade, sexo e tempo: "três aspectos da psicologia humana”. São Paulo: Agir, s/d.

MAGALDI, Ana Maria B. M. Lições de casa: discursos pedagógicos destinados à família no Brasil. 2001. Tese (Doutorado em História), Universidade Federal Fluminense, Niterói, 2001.

NARCIZO, Rodrigo Mota. "Ministro de Deus, portador da lu₹": ações e discursos católicos de modelação docente na década de 1930. Dissertação (Mestrado em Educação), Faculdade de Educação, Universidade do Estado do Rio de Janeiro, Rio de Janeiro, 2008.

ORLANDO, Evelyn de Almeida. "Educar-se para educar": O projeto pedagógico do Monsenhor Álvaro Negromonte dirigido a professoras e famílias através de impressos (1936-1964). 360f. Tese (Doutorado em Educação), Faculdade de Educação, Universidade do Estado do Rio de Janeiro, Rio de Janeiro, 2013.

PINSKY, Carla Bassanezi. Mulheres dos anos dourados. In: DEL PRIORE, Mary (org.). História das mulheres no Brasil. São Paulo: Contexto, 1997.

PINSKY, Carla Bassanezi. Mulheres nos anos dourados. São Paulo: Contexto, 2014.

SILVA, Luciandra Gonçalves da. "Sob o símbolo da cru₹": questão social, família e educação nas relações entre Estado e Igreja no Brasil (1930-1945). 145f. Dissertação (Mestrado em Educação), Faculdade de Educação, Universidade do Estado do Rio de Janeiro, Rio de Janeiro, 2010.

SOARES, Gabriela Pellegrino. Os irmãos Weiszflog em busca dos mercados escolares: Identidades das Edições Melhoramentos dos primórdios à década de 1960. In: BRAGANÇA, Aníbal; ABREU, Márcia. Impresso no Brasil: dois séculos de livros brasileiros. São Paulo: Editora UNESP, 2010.

TOLEDO, Maria Rita de Almeida. Coleção Atualidades Pedagógicas: do projeto político ao editorial (1931-1981). 296 f. Tese (Doutorado em Educação), Pontifícia Universidade Católica de São Paulo, São Paulo, 2001.

TOLEDO, Maria Rita de Almeida; CARVALHO, Marta Maria Chagas de. A tradução de John Dewey publicada na coleção Biblioteca de Educação. 2013. Disponível em http://sbhe.org.br/novo/congressos/cbhe7/pdf/08-\%20IMPRESSOS\%20INTELECTUAIS $\% 20 \mathrm{E} \% 20$ HISTORIA $\% 20 \mathrm{DA} \% 20 \mathrm{EDUCACAO} / \mathrm{A} \% 20$ TRADUCAO $\%$ 20DE $\% 20 \mathrm{JOHN} \% 20 \mathrm{DEWEY} \% 20 \mathrm{PUBLICADA} \% 20 \mathrm{NA} \% 20 \mathrm{COLECAO} \% 20 \mathrm{BIBLIOTECA} \%$ 20DA\%20EDUCACAO.pdf. Acesso em 30 abr. 2017.

VILHENA, Cardoso Carla; FERREIRA, Gomes, Antonio. Formar bem as mães para criar e educar boas crianças: as revistas portuguesas de educação familiar e a difusão da maternidade científica (1945-1958). História da Educação, Pelotas, v. 18, n. 44, set./ dez. 2014. Disponível em http://seer.ufrgs.br/index.php/asphe/article/view/43232. Acesso em 28 out. 2016.

VILHENA, Cynthia Pereira de Sousa. Família, mulher e prole: A doutrina social da Igreja e a política social do Estado Novo. Tese (Doutorado em Educação), Faculdade de Educação, Universidade de São Paulo, São Paulo, 1988. 


\section{Informações das autoras}

Evelyn de Almeida Orlando

Pontifícia Universidade Católica do Paraná

E-mail: evelynorlando@gmail.com

ORCID: https://orcid.org/0000-0001-5795-943X

Link Lattes: http://lattes.cnpq.br/5837085501572080

Henllyger Estevam David

Afiliação institucional Pontifícia Universidade Católica do Paraná E-mail: henllyger_estevam@hotmail.com

ORCID: https://orcid.org/0000-0003-3829-5863

Link Lattes: $\underline{\text { http://lattes.cnpq.br/2892244148667788 }}$ 